\title{
Phenotypic alteration of macrophages during osteoarthritis: a systematic review
}

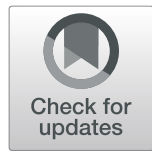

\author{
Xiaobo Zhu ${ }^{1,2}$, Chien-Wei Lee ${ }^{1,2,3}$, Hongtao Xu' ${ }^{2}$ Yu-Fan Wang ${ }^{2}$, Patrick S. H. Yung ${ }^{2}$, Yangzi Jiang ${ }^{1,3}$ and \\ Oscar K. Lee ${\text { L, } 2,4,5^{*}}_{\text {(D) }}$
}

\begin{abstract}
Objective: Osteoarthritis (OA) has long been regarded as a disease of cartilage degeneration, whereas mounting evidence implies that low-grade inflammation contributes to OA. Among inflammatory cells involved, macrophages play a crucial role and are mediated by the local microenvironment to exhibit different phenotypes and polarization states. Therefore, we conducted a systematic review to uncover the phenotypic alterations of macrophages during $\mathrm{OA}$ and summarized the potential therapeutic interventions via modulating macrophages.
\end{abstract}

Methods: A systematic review of multiple databases (PubMed, Web of Science, ScienceDirect, Medline) was performed up to February 29, 2020. Included articles were discussed and evaluated by two independent reviewers. Relevant information was analyzed with a standardized and well-designed template.

Results: A total of 28 studies were included. Results were subcategorized into two sections depending on sources from human tissue/cell-based studies (12 studies) and animal experiments (16 studies). The overall observation indicated that M1 macrophages elevated in both synovium and circulation during OA development, along with lower numbers of M2 macrophages. The detailed alterations of macrophages in both synovium and circulation were listed and analyzed. Furthermore, interventions against OA via regulating macrophages in animal models were highlighted.

Conclusion: This study emphasized the importance of the phenotypic alterations of macrophages in OA development. The classical phenotypic subcategory of M1 and M2 macrophages was questionable due to controversial and conflicting results. Therefore, further efforts are needed to categorize macrophages in an exhaustive manner and to use advanced technologies to identify the individual roles of each subtype of macrophages in OA.

Keywords: Osteoarthritis, Macrophage, Innate immunity, Immunomodulation

\section{Introduction}

Osteoarthritis (OA) is the most common degenerative joint disorder, mainly affecting the weight-bearing joints such as knees and hips [1], and the non-weight-bearing joints such as the hand and temporomandibular joints

\footnotetext{
*Correspondence: oscarlee9203@gmail.com

${ }^{1}$ Institute for Tissue Engineering and Regenerative Medicine, The Chinese University of Hong Kong, Hong Kong, China

${ }^{2}$ Department of Orthopaedics and Traumatology, Faculty of Medicine, The Chinese University of Hong Kong, Hong Kong, China

Full list of author information is available at the end of the article
}

[2]. OA is the main cause of physical disability and has been predicted to afflict approximately 67 million people in USA by 2030 [3]. Though risk factors such as aging, obesity, genetic predisposition, and joint trauma have been identified for OA initiation [4-7], few effective treatments are available to prevent OA due to the insufficient understanding of the pathogenesis [8]. Recently, accumulating evidence indicates that the inflammation significantly contributes to $\mathrm{OA}$ in addition to the abnormal mechanical loading [9]. OA is gradually viewed as a

(c) The Author(s). 2021 Open Access This article is licensed under a Creative Commons Attribution 4.0 International License, which permits use, sharing, adaptation, distribution and reproduction in any medium or format, as long as you give appropriate credit to the original author(s) and the source, provide a link to the Creative Commons licence, and indicate if changes were made. The images or other third party material in this article are included in the article's Creative Commons licence, unless indicated otherwise in a credit line to the material. If material is not included in the article's Creative Commons licence and your intended use is not permitted by statutory regulation or exceeds the permitted use, you will need to obtain permission directly from the copyright holder. To view a copy of this licence, visit http://creativecommons.org/licenses/by/4.0/ The Creative Commons Public Domain Dedication waiver (http://creativecommons.org/publicdomain/zero/1.0/) applies to the data made available in this article, unless otherwise stated in a credit line to the data. 
low-grade inflammatory disease affecting the whole joint besides articular cartilage [10]. Collectively, these findings highlight the profound role of innate immunity in the progression of $\mathrm{OA}$.

As a critical part of the innate immune system, macrophage has long been considered as an important participant in OA. For instance, depletion of synovium macrophages by magnetic beads (anti-CD14-conjugated magnetic beads) [11] or chemicals (e.g., clodronates) [12] contributes to decreasing cartilage catabolic enzymes such as MMP13 and Adamts4. However, the systemic ablation of macrophage in MaFIA (Macrophage Fas-Induced Apoptosis) mice leads to a severe synovitis in obese OA model, implying the complicated roles of macrophages in OA [13].

Macrophages play diverse roles in development, inflammation, and tissue repairing. The plasticity of macrophages enables the cells to make adjustments towards local microenvironments and respond to a wide range of stimuli under both physiological and pathological conditions [14, 15]. Studies in ferreting out the role of macrophages in inflammation have progressed recently. Researchers have identified two different polarization status of macrophages when confronted with different stimuli. In inflammatory phase, classically activated M1 macrophages are recruited and produce high levels of pro-inflammatory cytokines and chemokines, such as tumor necrosis factor-alpha (TNF- $\alpha$ ), IL-1, and IL-6. On the other hand, alternatively activated M2 macrophages are needed for the resolution of inflammation. M2 macrophages reverse the inflammatory process by releasing anti-inflammatory factors such as IL-10 and secreting growth factors, such as transforming growth factorbeta (TGF- $\beta$ ) [16]. Therefore, polarization of macrophages at different inflammatory stages might account for various pathological processes. Although the concept of macrophage M1/M2 polarization provides an effective system to study macrophages in vitro, the exact definition and phenotypic transition of macrophages in in vivo studies are still less defined [17].

As mentioned, emerging studies aimed to control inflammation in different diseases by targeting phenotypic changes of macrophages. In pre-clinical models, normalizing the aberrant M1/M2 ratio has been suggested as a therapeutic strategy for macrophageinvolved diseases, such as atherosclerosis, lung cancer, and bone diseases including osteoporosis and osteoarthritis [18-22].

In this study, we systematically reviewed recent key findings of macrophage polarization in $\mathrm{OA}$, evaluated the role of phenotypic alterations in macrophages, and summarized the current and potential interventions via the modulations of macrophages.

\section{Methods}

\section{Search strategy}

A systematic search was set up on PubMed, WOS (Web of Science), Ovid (MEDLINE database), Embase (Elsevier Database), and Science Direct (Elsevier Databases), according to the Preferred Reporting Items for Systematic Reviews and Meta-Analyses (PRISMA) guidelines [23]. It was performed without any limitation to the publication date in order to identify all articles on the role of M1 and M2 macrophages in OA. The medical term for osteoarthritis was used in combination with phenotypic alterations of macrophages, which was shown below: osteoarthritis [Title/Abstract] AND macrophage [Title/Abstract] AND (Polarization [Title/Abstract] OR polarization [Title/Abstract] OR M1 [Title/Abstract] OR M2 [Title/Abstract] OR inflammation [Title/Abstract]). The search was last updated on February 29, 2020.

\section{Screening process}

All articles were screened by two independent investigators (XBZ and HTX). The reviewing selection process was based on title, abstract, and full-text level, using a well-established screening tool, Covidence [24].

The eligibility of each article was determined according to the inclusion and exclusion criteria. Studies were included if they met the following criteria: (i) relevant to the searching strategy, (ii) English-written articles within the recent 20 years, and (ii) availability of full-length research articles. Exclusion criteria were present as following: nonEnglish written studies, case studies, review articles, editorials, letters, conference paper, or book chapters. Moreover, the contents of the articles were also taken into consideration. Studies that were not related to OA or without measurements of macrophages were excluded.

Studies meeting all criteria were included, and the quality assessment of these articles was based on heterogeneity and methodological quality. Methodological qualities of included studies were based on the quality systems, which were raised by Wells et al. [25-28]. Details about the qualities of the included studies were listed in Supplemental materials.

At each step of screening, a final consensus was reached after the mutual discussion between two investigators (XBZ and HTX) when different opinions existed. Data were extracted and tabulated by XBZ, and then, a subset of key variables was validated by HTX.

All included articles were double-checked by the third investigator (YFW). Similarly, relevant data were extracted and analyzed with a standardized method designed for this review (see Fig. 1. for the flowchart).

\section{Results}

Of the 920 articles screened that were considered to be relevant to the research topic, 28 articles were finally 


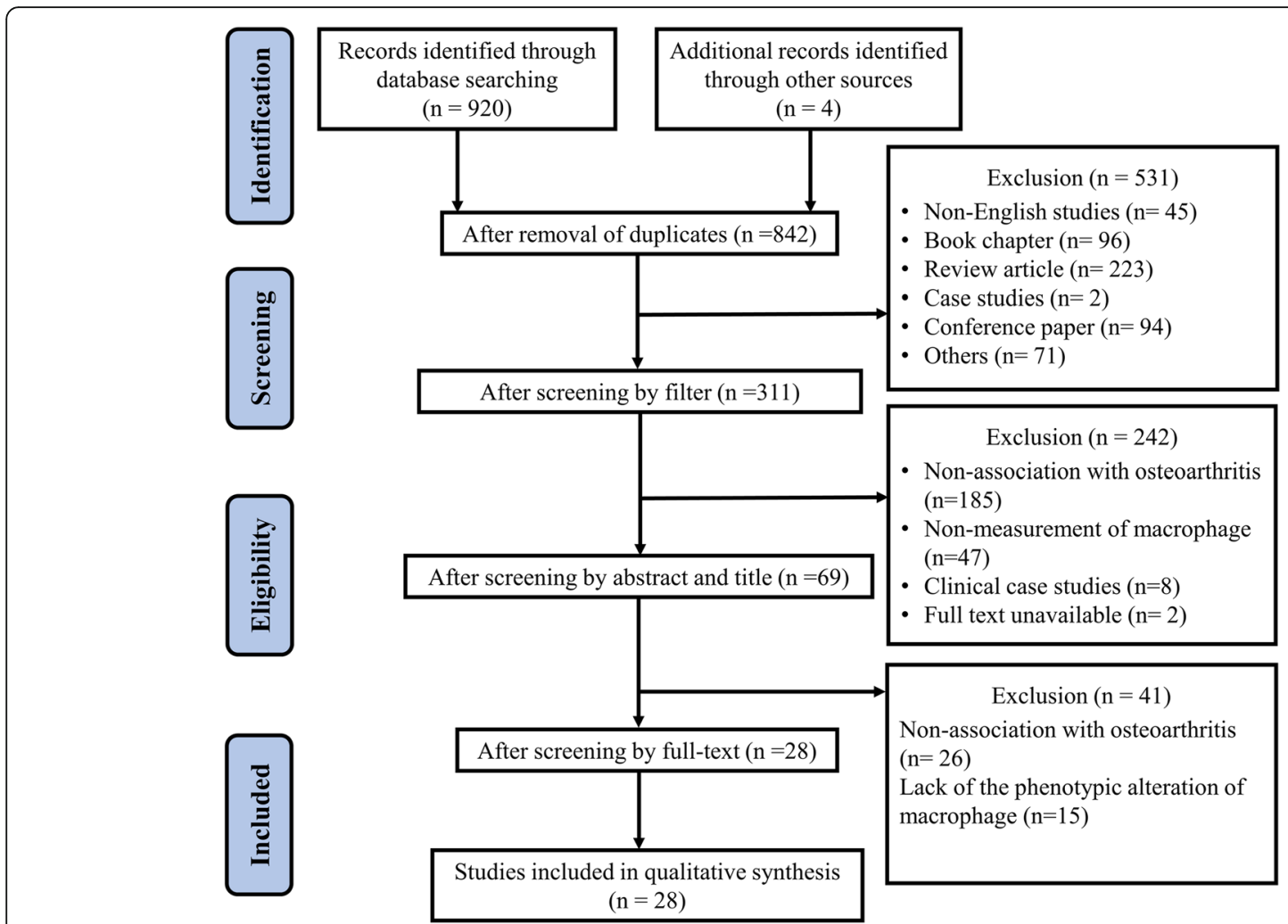

Fig. 1 Flowchart of studies included in the systematic review. After the application of all inclusion and exclusion criteria, 28 studies were identified for analysis

included. The screening process is available in Fig. 1. The detailed information of the 28 selected articles are shown in Table 1. In this review, the included articles were categorized into two sections based on the species as different species have different cellular compartments [56]. The distributional proportions of all species in included articles are shown in Fig. 2a. Among all included articles, studies focusing on tissues or cells from human species constituted less than half of total (12/28), followed by animal studies (16/28), including mouse (9/ $28)$, rat $(4 / 28)$ and other animals (canine and equine studies, 3/28). Within these two subcategories (humanderived and animal studies), the origin of macrophages was also evaluated, especially for the peripheral macrophages (peripheral blood monocyte-derived macrophages) and the tissue-resident macrophages (synovial macrophages). In each subcategory, further evaluation was conducted on the interventions that could impact or modulate the M1/M2 ratio in OA progression.

\section{Human tissue/cell-based studies}

In mammals, most organs contain tissue-resident macrophages. These macrophages are believed to be distributed into different tissues during embryogenesis [15] and are essential for maintaining immune homeostasis.
On the other hand, circulating monocyte-derived macrophages also play a crucial role in inflammation. In response to inflammation, circulating monocytes are recruited to inflamed tissues and subsequently differentiate into macrophages in situ by local inflammatory mediators [57]. For healthy individuals, a small number of macrophages constitutively reside in the knee joint. However, in the OA knees, the intensity and infiltrated areas of macrophages in synovium are significantly increased [58].

\section{M1 and M2 macrophage in the peripheral blood from $O A$ patients}

Studies of peripheral blood monocytes (PBMCs) in OA were carried out in the past few years. PBMCs would partially polarize towards M1 or M2 macrophages after stimuli, and the phenotypic alterations of macrophages were identified based on cellular markers.

In one study, PBMCs were isolated and induced to differentiate into macrophages, and then, $\mathrm{CD} 14^{+} \mathrm{CD} 11 \mathrm{~b}^{+}$ macrophages (M0, naive macrophages) were purified and selected. Upon stimulated with OA-related metabolite, such as basic calcium phosphate (BCP) crystals, macrophages produced higher levels of chemokines, such as CXCL9 and CXCL10, and increased the expression of 
Table 1 Characteristics and major conclusion of included studies

\begin{tabular}{|c|c|c|c|c|}
\hline Author & Cell source & Species & $\begin{array}{l}\text { Study } \\
\text { type }\end{array}$ & Conclusions \\
\hline $\begin{array}{l}\text { Mahon et al. } \\
\text { [29] }\end{array}$ & PBMC & Human & In vitro & $\begin{array}{l}\mathrm{BCP} \text { promotes macrophage } \mathrm{M} 1 \text { polarization during } \mathrm{OA} \text { pathogenesis } \\
2 \mathrm{DG} \text { reverses } \mathrm{BCP} \text {-induced } \mathrm{M} 1 \text { polarization in } \mathrm{OA}\end{array}$ \\
\hline $\begin{array}{l}\text { Zhou et al. } \\
\text { [30] }\end{array}$ & RAW264.7 & Mouse & $\begin{array}{l}\text { In vitro \& } \\
\text { In vivo }\end{array}$ & $\begin{array}{l}\text { ACLT model induces an increase of M1 polarization in synovial macrophage. } \\
\text { Kin attenuates the number of M1 macrophage and up-regulated the M2 macrophage. }\end{array}$ \\
\hline $\begin{array}{l}\text { Jablonski et al. } \\
\text { [31] }\end{array}$ & N/A & Mouse & In vivo & $\begin{array}{l}\text { The predominant macrophage population observed in uninjured knee joint is M1 } \\
\text { macrophage. }\end{array}$ \\
\hline $\begin{array}{l}\text { Benjamin } \\
\text { et al. [32] }\end{array}$ & N/A & Dog & In vivo & CR (cruciate rupture) model leads to a M1 polarization in synovial macrophage. \\
\hline $\begin{array}{l}\text { Haltmayer } \\
\text { et al. [33] }\end{array}$ & N/A & Horse & In vitro & $\begin{array}{l}\text { The osteochondral-synovial explant co-culture OA-model indicates a shift towards M1 } \\
\text { phenotype during OA progression }\end{array}$ \\
\hline Liu et al. [34] & $\begin{array}{l}\text { Synovial fluid; } \\
\text { PBMC }\end{array}$ & Human & In vivo & $\begin{array}{l}\text { Human knee synovial macrophage displays an increased M1 polarization and decreased } \\
\text { M2 polarization. }\end{array}$ \\
\hline $\begin{array}{l}\text { Sambamurthy } \\
\text { et al. [35] }\end{array}$ & N/A & Mouse & In vivo & $\begin{array}{l}\text { DMM model presents an elevated M1 polarization and decreased M2 polarization during } \\
\text { OA progression }\end{array}$ \\
\hline $\begin{array}{l}\text { Wang et al. } \\
{[36]}\end{array}$ & BMMC & Mouse & $\begin{array}{l}\text { In vivo \& } \\
\text { In vitro }\end{array}$ & $\begin{array}{l}\text { DMM model demonstrates increased numbers of } \mathrm{M} 1 \text { macrophages and decreased } \\
\text { number of M2 macrophage. BTZ could reversed this pathological process }\end{array}$ \\
\hline $\begin{array}{l}\text { Zhang et al. } \\
\text { [37] }\end{array}$ & Synovium & Mouse & In vivo & Both human $\mathrm{OA}$ and $\mathrm{CIOA}$ model display an elevated M1 polarization \\
\hline $\begin{array}{l}\text { Timur et al. } \\
{[38]}\end{array}$ & Hoffa's fat pad & Human & In vivo & $\begin{array}{l}\text { PGE2 released by OA HFP is positively associated with } \mathrm{M} 1 \text { macrophages polarization, } \\
\text { indicating a role for macrophages. Celecoxib modulated the inflammation ratio towards a } \\
\text { more favorable anti-inflammatory } \mathrm{M} 2 \text { phenotype }\end{array}$ \\
\hline $\begin{array}{l}\text { Topoluk et al. } \\
\text { [39] }\end{array}$ & $\begin{array}{l}\text { Synovium and } \\
\text { cartilage explant }\end{array}$ & Human & In vitro & OA coculture of synovium with cartilage demonstrates increased M1 polarization. \\
\hline Wu et al. [13] & N/A & Mouse & In vivo & DMM model demonstrates increased numbers of $\mathrm{M} 1$ macro \\
\hline $\begin{array}{l}\text { Manferdini } \\
\text { et al. [40] }\end{array}$ & $\begin{array}{l}\text { Human SMMC \& } \\
\text { PBMC }\end{array}$ & Human & In vitro & $\begin{array}{l}\text { ASCs are responsible for the switching of activated-M1-like inflammatory macrophages to } \\
\text { a M2-like phenotype }\end{array}$ \\
\hline Pal et al. [41] & PBMC & Human & In vitro & $\begin{array}{l}\text { SFN could shift monocyte/macrophage differentiation towards the anti-inflammatory M2 } \\
\text { type }\end{array}$ \\
\hline $\begin{array}{l}\text { Siebelt et al. } \\
{[42]}\end{array}$ & Human monocyte & Rat & In vitro & TA induces a M2 polarization in macrophage \\
\hline Fahy et al. [43] & $\begin{array}{l}\text { SMMC and } \\
\text { fibroblast }\end{array}$ & Human & In vitro & M1 macrophages downregulate MSC chondrogenesis \\
\hline $\begin{array}{l}\text { Tsuneyoshi } \\
\text { et al. [44] }\end{array}$ & N/A & Human & In vitro & $\begin{array}{l}\text { The distribution and M1/M2 expression profiles of synovial macrophages are different } \\
\text { between } O A \text { and RA synovium. }\end{array}$ \\
\hline $\begin{array}{l}\text { Zhang et al. } \\
{[45]}\end{array}$ & N/A & Rat & In vivo & $\begin{array}{l}\text { In a Rat osteochondral defect model, M2 macrophages in cartilage and synovium } \\
\text { increase. The intervention of exosomes increases the M2 macrophages and decreases M1 } \\
\text { macrophage }\end{array}$ \\
\hline Hu et al. [46] & N/A & Rat & In vivo & $\begin{array}{l}\text { Quercetin promotes cartilage repair by modulating macrophages polarization to M2 } \\
\text { macrophages in Rat OA model }\end{array}$ \\
\hline Dai et al. [47] & RAW264.7 & Rat & $\begin{array}{l}\text { In vivo \& } \\
\text { In vitro }\end{array}$ & $\begin{array}{l}\mathrm{SCll} \text { immunomodulates a phenotype shift of macrophages from M0 to M2 during OA } \\
\text { progression }\end{array}$ \\
\hline $\begin{array}{l}\text { Barreto et al. } \\
{[48]}\end{array}$ & PBMC & Human & In vitro & $\begin{array}{l}\text { Lumican contributes to the innate immune-mediated pathogenesis of primary IOA via } \\
\text { macrophage M1 polarization }\end{array}$ \\
\hline $\begin{array}{l}\text { Kraus et al. } \\
{[49]}\end{array}$ & N/A & Human & In vivo & One patient $\mathrm{OA}$ synovium presents $\mathrm{M} 1$ and $\mathrm{M} 2$ marker simultaneously. \\
\hline $\begin{array}{l}\text { Utomo et al. } \\
\text { [50] }\end{array}$ & PBMC & Human & In vitro & Dexamethasone lowers M1/M2 proportion in OA synovium. \\
\hline $\begin{array}{l}\text { Perla et al. } \\
\text { [51] }\end{array}$ & $\begin{array}{l}\text { THP-1 cell; } \\
\text { PBMC }\end{array}$ & Human & In vitro & $\begin{array}{l}\text { Overexpression of CD163 contributes the transition from M1 to M2 when stimulated with } \\
\text { LPS }\end{array}$ \\
\hline $\begin{array}{l}\text { Nobuaki et al. } \\
\text { [52] }\end{array}$ & N/A & Mouse & In vivo & $\begin{array}{l}\text { Polarization towards M2-like macrophages from M1-like macrophages in the synovium is } \\
\text { associated with OA alleviation by SRT2104. }\end{array}$ \\
\hline $\begin{array}{l}\text { Menarim et al. } \\
\text { [53] }\end{array}$ & BMMC & Horse & In vitro & $\begin{array}{l}\text { BMNCs cultured in normal synovial fluid or inflamed synovial fluid exhibit aspects of both } \\
\text { M1 and } \mathrm{M} 2 \text { phenotypes and immunoregulatory response. }\end{array}$ \\
\hline
\end{tabular}


Table 1 Characteristics and major conclusion of included studies (Continued)

\begin{tabular}{lllll}
\hline Author & Cell source & Species & $\begin{array}{l}\text { Study } \\
\text { type }\end{array}$ & Conclusions \\
\hline $\begin{array}{l}\text { Zhou et al. } \\
{[54]}\end{array}$ & RAW264.7 & Mouse & $\begin{array}{l}\text { In vivo \& } \\
\text { In vitro }\end{array}$ & $\begin{array}{l}\text { Modified Nanoparticles suppress M1 macrophages and upregulate M2 macrophage } \\
\text { infiltration in the synovium, thus preventing cartilage degeneration }\end{array}$ \\
Shu et al. [55] & N/A & Mouse & In vivo & $\begin{array}{l}\text { Hyaluronan could increase the anti-fibrotic M2C macrophages }\left(\mathrm{F} 4 / 80^{+} \mathrm{CD} 206^{+} \mathrm{CD} 301^{+}\right) 12 \\
\text { weeks post DMM }\end{array}$ \\
\hline
\end{tabular}

Abbreviations: PBMC peripheral blood monocytes, SMM synovium-derived macrophage, BMMC bone marrow mononuclear cells

M1 surface markers, such as CD86 and CD40 [29]. These results implied that the PBMCs tended towards the M1 phenotype during OA.

In another human cell-based study, the proportion of pro-inflammatory $\mathrm{CD} 11 \mathrm{c}^{+}$macrophages was significantly higher in the circulation of OA patients than that of healthy individuals. In contrast, the number of antiinflammatory CD206 ${ }^{+}$macrophages was markedly lower in OA patients [34]. These results revealed a higher M1/ M2 ratio in the peripheral blood of OA patients.

\section{M1 and M2 macrophage in synovium from OA patients}

Synovium-resident macrophages were activated in OA and contributed to the principal source of cytokines in OA progression [59].
Researchers have identified the abnormal accumulation and phenotypic alterations of macrophages in $\mathrm{OA}$ synovium $[44,49]$, analogous to those in the peripheral blood. Compared to healthy synovium, OA synovium demonstrated a marked elevation of $\mathrm{F} 4 / 80^{+}$(macrophage marker) cells in both intimal and sublining layers, together with a higher number of iNOS ${ }^{+}$(M1-like macrophage marker) cells in the intimal lining layer. Conversely, CD206 ${ }^{+}$(M2-like macrophage marker) cells showed only a slight but non-significant decrease in OA synovium [37].

Hoffa's fat pad (HFP) is another macrophage niche in the knee joints [60]. Timur et al. divided the OA conditions into two groups according to the level of Prostaglandin $\mathrm{E} 2\left(\mathrm{PGE}_{2}\right)$ in HFP explant culture medium (100

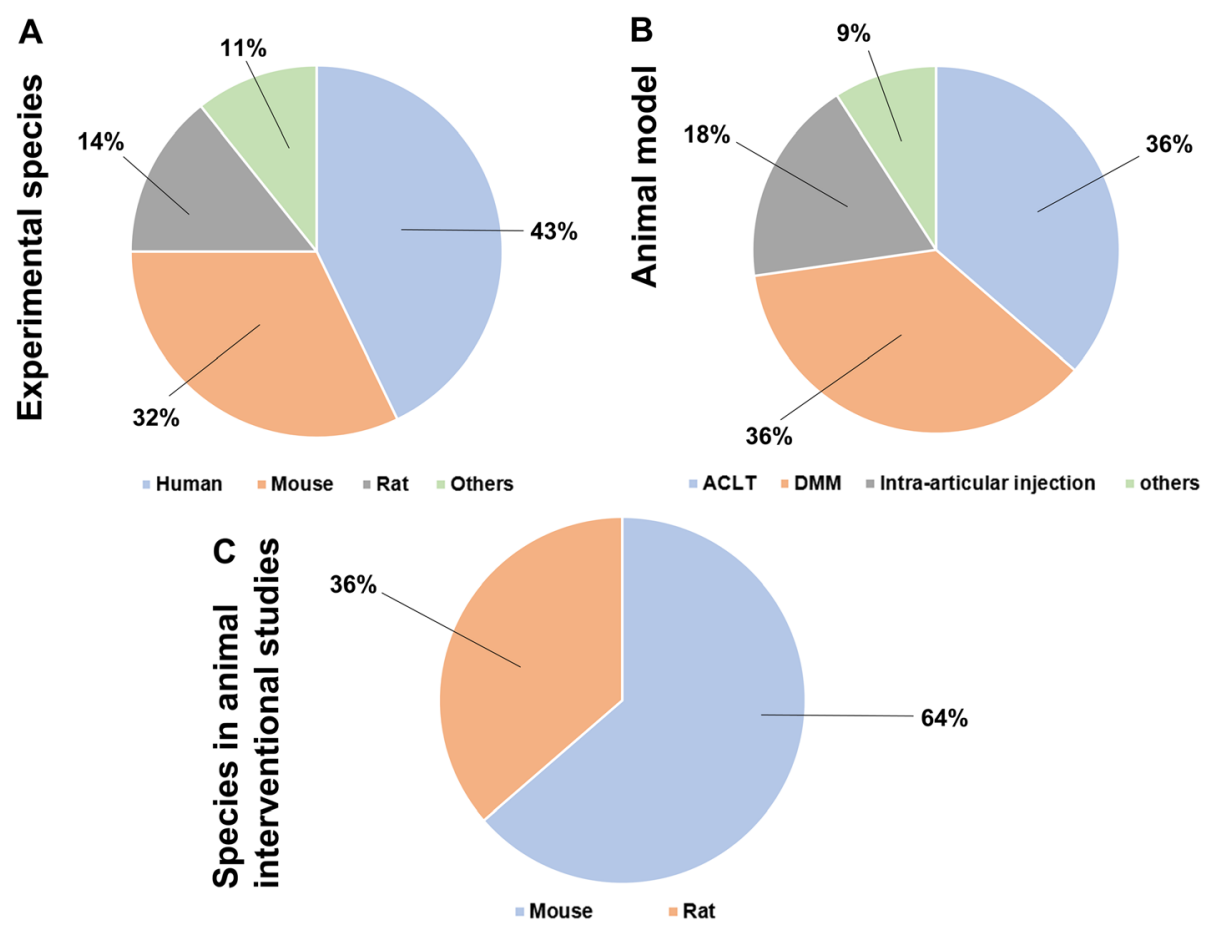

Fig. 2 Characteristic outcomes of experimental species, animal models, and species distribution in animal interventional studies. a The proportion of experimental species. $43 \%$ studies (12/28) were based on primary cells or samples from human. $32 \%$ studies (9/28) were based on primary cells or samples from mice. $14 \%$ studies (4/28) were based on primary cells or samples from rats. $11 \%$ of studies (3/28) were based on samples from canine and equinel; b Pie chart illustrating the types of animal models used in the studies. 36\% the animal models were ACLT (4/11). 36\% the animal models were DMM (4/11). 18\% the animal models were intra-articular injection of collagenase (2/11). 9\% the animal models were other animal models including osteochondral defect model (1/11); c Species distribution in interventional animal studies. $64 \%$ the interventional studies were based on mouse models. $36 \%$ the interventional studies were based on rat models 
$\mathrm{mg}$ fat pad tissue $/ \mathrm{ml}$ ): high $\mathrm{PGE}_{2}$ group $(>25 \mathrm{ng} / \mathrm{ml}$ ) and low $\mathrm{PGE}_{2}$ group $(<25 \mathrm{ng} / \mathrm{ml})$. The HFP from high $\mathrm{PGE}_{2} \mathrm{OA}$ group showed a 21.4-fold higher inflammation ratio than HFP from low $\mathrm{PGE}_{2} \mathrm{OA}$ group. Meanwhile, HFP from high $\mathrm{PGE}_{2} \mathrm{OA}$ group demonstrated 3.7-fold lower gene expression of CD163 (M2 macrophage marker) compared to the HFP in low PGE2 group. These results indicated that the role of macrophage polarization might vary in different OA subtype [38].

\section{In vitro human tissue/cell-based study}

Although the in vitro data from isolated cells or tissues are not yet ready to be translated into clinical interventions in OA. Several in vitro studies with exogenous treatment still showed potentials to normalize the macrophage polarization and protect against OA. For example, overexpression of CD163 in primary human macrophages by a polyethylenimine nanoparticles grafted with a mannose ligand (Man-PEI) contributed to the transition of macrophages from M1 to M2 after being stimulated with LPS [51]. Pal et al. validated that sulforaphane $(10 \mu \mathrm{M})$ could skew the differentiation of monocytes (human monocyte cell line: THP1 cells; human primary monocytes) towards the anti-inflammatory M2 type [41]. Another sample is lumican (LUM), a major extracellular matrix glycoprotein in articular cartilage, and its expression was significantly upregulated in OA [48]. LUM contributed to the innate immune-mediated pathogenesis of primary OA via promoting macrophage M1 polarization [48], and this made LUM become a promising therapeutic target for OA. In addition, the human adipose-derived MSCs were reported to be responsible for phenotypic switching from M1 to M2 in human macrophages, accompanied with the decreased secretion of inflammatory cytokines such as TNF$\alpha$ and IL-6 [40]. These cellular and molecular mechanisms are related to the modification of macrophages in OA, and the treatments have shown therapeutic effects in human in vitro studies.

\section{Animal studies}

Due to the complexity of OA, there are still many unknowns in pathogenesis of OA. For example, the exact trigger for initiating the cartilage degradation is still unknown. Also, the underlying mechanisms that lead to disease maintenance rather than resolution are still poorly understood. Therefore, animal studies become valuable to delineate the underlying mechanisms of the disease and develop novel therapies.

In this section, we reviewed the articles on the phenotypic alterations of macrophages in different species and different animal models. Since there are many different types of OA animal models, the proportion of different OA models applied in the included studies is shown in Fig. 2b.

\section{M1 and M2 macrophages in synovium from experimental animals}

Destabilization of medial meniscus (DMM)-induced OA, a well-established OA model [61], has been widely used to study the macrophage alterations in OA. Four studies were included with DMM model in this section, and all studies reported a significantly higher number of synovial $\mathrm{F} 4 / 80^{+}$cells post $\mathrm{DMM}$, indicating that the innate immune system was activated during DMM-incurred OA progression. One study drew the conclusion that the number of $\mathrm{M} 1$ macrophages $\left(\mathrm{F} 4 / 80^{+} \mathrm{CD} 86^{+} \mathrm{CD} 63^{-}\right)$was significantly increased in murine synovium 6 weeks after DMM [36]. In another study, synovial $\mathrm{F} 4 / 80^{+} \mathrm{CD} 11 \mathrm{c}^{+} \mathrm{CD} 206^{+}$ cells significantly decreased after DMM for both 4 and 8 weeks [35]. Additionally, another study showed a trend towards more $\mathrm{NOS2}^{+}$cells (M1 macrophages) in the DMM-operated joint than those in contralateral joint [36]. Similar trends in the change of macrophage populations were also found in a more severe OA model, anterior cruciate ligament transection (ACLT)-induced rodent OA model [30, 47].

Furthermore, there were three studies in large animals. One was a canine OA model [32], and two were equine OA models [53, 62]. In the canine study, synovial fluid samples were collected and analyzed, and researchers discovered that ratio of positively stained M1-polarized macrophages $\left(\mathrm{CCR}^{+}{ }^{+} \mathrm{NOS}^{+} \mathrm{CD}^{+} 8^{+}\right.$cells) to M2-polarized macrophages $\left(\mathrm{CD}_{163}{ }^{+} \mathrm{Arg} 1^{+} \mathrm{CD} 68^{+}\right.$cells) was higher in OA group than that in the normal control group [32]. In an ex vivo study, the equine osteochondral-synovial explant co-culture system was facilitated as an OA model. Researchers evaluated the ratio of $\mathrm{NO}(\mu \mathrm{M}) /$ urea $(\mu \mathrm{M})$ as a symbol of pro-inflammatory M1-like macrophages as previously described [63] and concluded that the macrophages underwent a shift towards M1 phenotype during OA progression [33]. Recently, another study demonstrated that bone marrow-derived mononuclear cells, which were viewed as a source of macrophages, displayed an M2-like transcriptional characteristics when stimulating with inflamed synovial fluid in an equine OA synovitis model $(0.5 \mathrm{ng}$ LPS injection into radiocarpal joint for $8 \mathrm{~h}$ ) [53].

It was also noteworthy that though the phenotypic alterations of macrophages during rheumatoid arthritis (RA) had already been discovered recently $[64,65]$, there was still a knowledge gap in the phenotypic alterations of peripheral blood-derived monocytes or macrophages in OA animal models.

\section{Interventions in animal models}

Among all included animal studies, 11 studies were selected and highlighted for the interventions against abnormal changes of macrophages. As shown in Fig. 2c, 64\% of these studies (7/11) were based on the mouse models while $36 \%$ of the studies $(4 / 11)$ were based on the rat 
model. Researchers utilized diverse methodologies to correct the aberrant macrophage polarization (Fig. 3 and Table 2), including interventions regulating and targeting specific signaling pathways [31, 37, 52, 54] and comprehensive interventions such as extracts from traditional Chinese herbs [30, 46, 47], anti-inflammation drugs [42], mesenchymal stem cell (MSC)-related therapies $[45,55]$, and others [36].

For animal OA models, various traditional Chinese herb extracts such as kinsenoside, quercetin, and squid type II collagen were identified to be able to repolarize the synovial macrophages and attenuate cartilage degeneration in OA [30, 46, 47].

Moreover, to further elucidate the endogenous immunological mechanism of $\mathrm{OA}$, endogenous molecules and the relevant signaling pathways were identified. Mammalian target of rapamycin complex 1 (mTORC1) signaling pathway was reported to be aberrantly activated in synovial macrophages during $\mathrm{OA}$ and subsequently contributed to macrophage M1 polarization. These polarized macrophages (M1) produced excessive R-spondin-2 (Rspo2) and then exacerbated experimental OA [37]. By intra-articular injection of Rspo2 neutralizing antibody, the cartilage degeneration incurred by M1 macrophage polarization was effectively ameliorated [37]. In addition, activating silent information regulator
2 ortholog 1 (Sirt1) signaling pathway with a selective Sirt1 activator SRT210 relieved DMM-induced OA, partially through normalizing the synovial macrophage polarization (increased the $\mathrm{CD}_{206^{+}} \mathrm{M} 2$ macrophages and decreased the iNOS $^{+}$M1 macrophages) [52]. With the development of nanotechnology, a modified nanoparticle (NP) termed zeolitic imidazolate framework-8 nanoparticle (ZIF-8 NP) was designed to target synovial macrophages and transform macrophage polarization from M1 to M2 phenotype, thus attenuating OA [54]. These interventions and signaling pathways are integrated in Table 3.

Stem cell-based therapies were also found to relieve OA via modulating macrophage activation [66]. The application of stem cells for cartilage repair relied on their ability to differentiate into chondrocytes and then substitute for the degenerative or dead chondrocytes [67]. Recent studies revealed that the reparative potential of MSCs for OA was also based on its immunological modification on the macrophages $[39,68]$. The administration of human embryonic stem cell-derived exosomes in the osteochondral defect model could increase the $\mathrm{CD}_{163}{ }^{+}$macrophages (M2) and decrease the CD86 ${ }^{+}$ macrophages (M1) in the joint, and lowered the levels of inflammatory cytokines inside the joint (cartilage and synovium) [68, 69]. Inversely, as a feedback, the

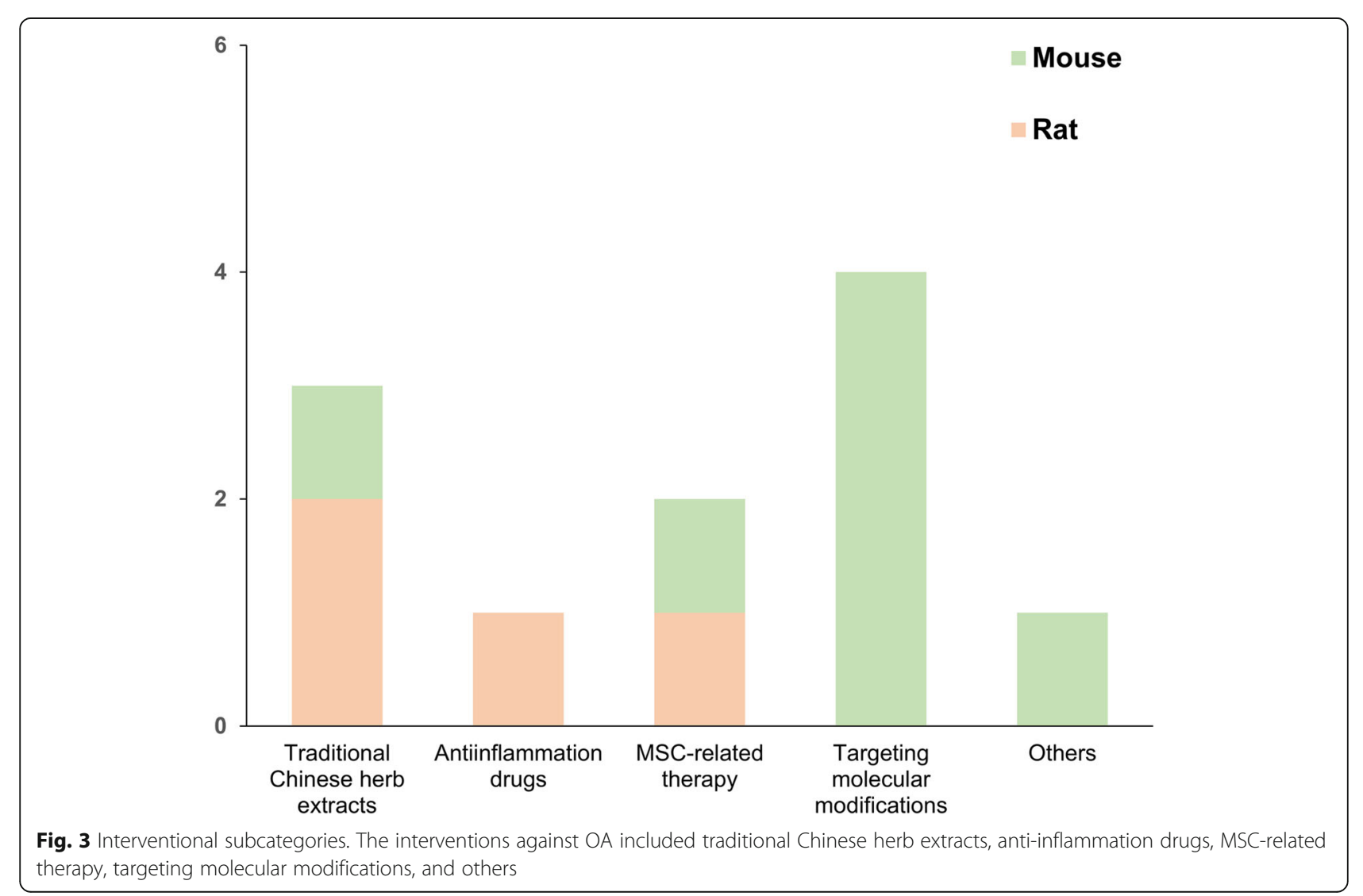


Table 2 Details of the interventions in the included studies

\begin{tabular}{|c|c|c|c|c|}
\hline Author & Category & Intervention & Detected marker & $\begin{array}{l}\text { Interventional } \\
\text { site }\end{array}$ \\
\hline $\begin{array}{l}\text { Jablonski } \\
\text { et al. [31] }\end{array}$ & $\begin{array}{l}\text { Endogenous } \\
\text { molecule }\end{array}$ & $\begin{array}{l}\text { Cartilage regeneration model; } \\
\text { Cartilage regeneration model in } \\
\mathrm{CCR}^{-1-} \mathrm{CCL}^{-1-} \text { mouse }\end{array}$ & $\begin{array}{l}\text { Cartilage regeneration model: } \mathrm{M} 1: \mathrm{CD} 38^{+} \uparrow ; \\
\text { Cartilage regeneration model in } \mathrm{CCR} 2^{-{ }^{-}} \mathrm{CCL} 2^{-/-} \text {mouse: } \\
\mathrm{M} 2: \mathrm{CD} 206^{+} \mathrm{F} 4 / 80^{+} \uparrow\end{array}$ & Joint \\
\hline $\begin{array}{l}\text { Zhang et al. } \\
\text { [37] }\end{array}$ & & $\begin{array}{l}\text { Mouse OA model; } \\
\text { Rheb1 Knockout }(\mathrm{KO}) \text { in myeloid cells }\end{array}$ & 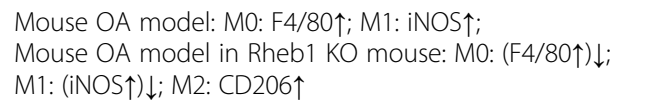 & Joint \\
\hline $\begin{array}{l}\text { Zhou et al. } \\
\text { [54] }\end{array}$ & & $\begin{array}{l}\text { Mouse OA model; } \\
\text { Modified ZIF-8 Nanoparticles }\end{array}$ & 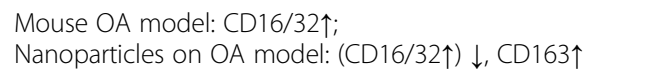 & Joint \\
\hline $\begin{array}{l}\text { Nobuaki } \\
\text { et al. [52] }\end{array}$ & & $\begin{array}{l}\text { Mouse OA model; } \\
\text { SRT2104 (SIRT1 activator) }\end{array}$ & 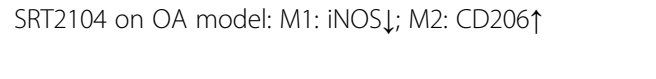 & Joint \\
\hline $\begin{array}{l}\text { Siebelt et al. } \\
\text { [42] }\end{array}$ & $\begin{array}{l}\text { Anti- } \\
\text { inflammation }\end{array}$ & Triamcinolone acetonide (TA) & TA: M2: CD163个 & Joint \\
\hline $\begin{array}{l}\text { Zhang et al. } \\
\text { [45] }\end{array}$ & $\begin{array}{l}\text { MSC-related } \\
\text { option }\end{array}$ & Exosomes & 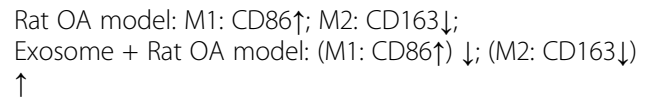 & Joint \\
\hline $\begin{array}{l}\text { Shu et al. } \\
\text { [55] }\end{array}$ & & $\begin{array}{l}\text { Mouse OA model; } \\
\text { Bone marrow stem cell (BMSC) }\end{array}$ & Hyaluronan:M2C (F4/80+CD206 $\left.{ }^{+} \mathrm{CD} 301^{+}\right) \uparrow$ & Joint \\
\hline $\begin{array}{l}\text { Zhou et al. } \\
\text { [30] }\end{array}$ & $\begin{array}{l}\text { Traditional } \\
\text { Chinese herb }\end{array}$ & Kinsenoside (Kin) & 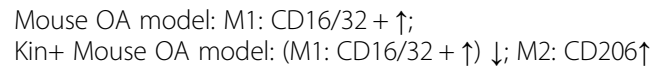 & Joint \\
\hline Hu et al. [46] & & Quercetin & 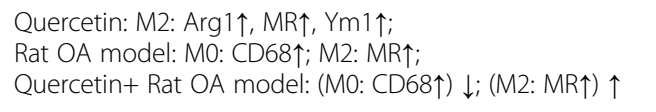 & Joint \\
\hline $\begin{array}{l}\text { Dai et al. } \\
{[47]}\end{array}$ & & Squid type II collagen (SCII) & 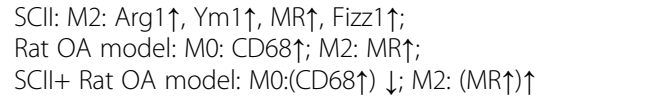 & Joint \\
\hline $\begin{array}{l}\text { Wang et al. } \\
\text { [35] }\end{array}$ & Others & $\begin{array}{l}\text { Mouse OA model } \\
\text { Bortezomib (BTZ) }\end{array}$ & 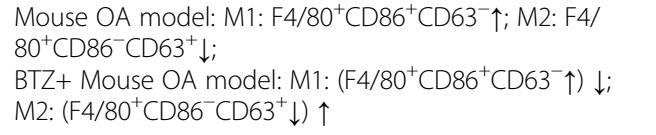 & Joint \\
\hline
\end{tabular}

Noted:

$\uparrow$ increase, $\downarrow$ decrease, Arg1 Arginase 1, CCL2 chemokine (C-C motif) ligand 2, CCR2 chemokine C-C motif receptor 2, Rheb1 Ras homolog enriched in brain 1

inflammatory microenvironment also impacted chondrogenic differentiation of mesenchymal stem cells via macrophage polarization [43].

\section{Discussion}

Recently, the crucial role of synovium resident macrophages in the pathogenesis of RA has been well recognized. Depletion of macrophages or normalizing macrophage phenotype could protect against RA [70-72], and the exact role of M1 and M2 macrophages in RA has also been well reviewed [73]. However, little has been systematically reviewed on the role of macrophages and their polarization in OA. In this study, we systematically

Table 3 Underlying therapeutic signaling pathway

\begin{tabular}{ll}
\hline Signaling pathway & Interventional site \\
\hline mTORC1-Rheb1/TSC1 [37] & Cartilage \\
Sirt1 [52] & Cartilage \\
CCL2-CCR2 [31] & Cartilage \\
Oxygen and hydrogen peroxide [54] & Synovium \\
\hline
\end{tabular}

reviewed the properties of M1 and M2 macrophages in the periphery, synovial tissue, and synovial fluids of OA patients. We presented important findings from both human and animal OA models and summarized the relevant targeting interventions or comprehensive interventions in these studies, which gave rise to normalizing the phenotype of macrophage (M1 or M2) and alleviating the OA progression.

However, some experimental results were relatively contradictory, which suggest that macrophages have multifaceted and complicated roles in OA. In a DMMinduced OA model in obese mice (high-fat diet for 10 weeks and 20 weeks), Wu et al. eliminated macrophages globally with a small molecule named AP20187 in MaFIA mice. The macrophage-deleted mice immediately exhibited less osteophyte formation following DMM, but these obese mice failed to relieve cartilage deterioration at week 9 and synovial inflammation was also activated in macrophage-depleted mice compared to that in nondepletion mice at week 9 [13]. These observations were inconsistent with previous studies conducted by Blom et al. that deletion of macrophages via intra-articular 
injection of clodronate liposomes could relieve the inflammatory response and cartilage catabolic enzymes in a collagenase-induced $\mathrm{OA}$ model in $\mathrm{C} 57 \mathrm{Bl} / 6$ mice [12, 74]. Further, $\mathrm{Wu}$ et al. also found that $\mathrm{CD}^{+}{ }^{+} \mathrm{T}$ cells and neutrophils massively infiltrated into the DMM-operated knee joint and caused severe joint synovitis [13]. The above study emphasized the potential roles of macrophage in maintaining joint homeostasis after injury apart from pro-inflammation and implied that macrophage would participate in limiting the adaptive immune response that developed after the initial innate response. Thus, it was arbitrary to treat OA by merely deleting whole macrophages in the joint, without discriminating the different subtypes of macrophages. Further attention should be paid to identifying and mobilizing the potential positive roles of macrophages on cartilage repair in OA.

Coincidently, Zhang et al. furthered the research on identifying the roles of different phenotypes of macrophages in OA [37]. They demonstrated that M1 but not M2 macrophages accumulated in synovial tissues from human OA and murine collagenase-induced OA. Activating synovial macrophage $\mathrm{M} 2$ polarization by ablating an upstream activator of mTORC1 pathway (i.e., Ras homolog enriched in brain 1/Rheb1) in myeloid lineage cells prevented OA development. Conversely, deleting an upstream inhibitor of mTORC1 pathway (i.e., tuberous sclerosis complex 1/TSC1) in myeloid lineage cells enhanced M1 polarization and exacerbated cartilage damage in both surgically induced OA and collagenaseinduced OA [37]. Furthermore, they identified Rspondin-2 (Rspo2) as an M1 macrophage-produced protein involved in the subsequent OA progression. Thus, clinical attention could be paid to the mTORC1 signaling pathways in synovial macrophages, and the administration of Rspo2 inhibitor or neutralizing antibody in the knee joints. Based on Zhang's study, the previous conflicting results (Blom's and Wu's studies) that global depletion of macrophages failed to prevent OA might be partially explained. We made the speculation that it was the phenotypic shift (e.g., from M0 to M1 by downregulating TSC1; from M0 to M2 by downregulating Rheb1), other than the number of macrophages that accounted for the conflicting results.

Understanding phenotypic changes of macrophage polarization and the function of each subtype would shed light on the potential clinical implication of the interventions. For instance, regenerative therapies such as human embryonic stem cell-derived exosomes showed potential to prevent cartilage deterioration via activating the pro-survival Akt signaling pathway, and reprogramming joint macrophage by increasing M2 transition and decreasing M1 macrophage infiltration [45]. Intriguingly, a recently developed nanoparticle (modified ZIF-8 NP) showed the similar therapeutic effects on cartilage protection and macrophage repolarization (described in 3.2.2) [54]. Thus, although the macrophage repolarization in OA is still under pre-clinical investigation, it is of great value to attach more importance to regulating macrophage polarization with the respect to the potential clinical application and successful application cases in other skeletal disease such as RA [72, 75].

Emerging improvements regarding the correlation of $\mathrm{OA}$ and macrophages have been made these years, but a number of unanswered questions were remained. Firstly, the classical M1/M2 classification was insufficient for researchers to describe and explain the delicate mechanisms, and the subtypes of macrophages were required to be delineated strictly. Although several subtypes of M2 macrophages (e.g., M2a, M2b, M2c, M2d) [76] were categorized based on the in vitro inducing cytokine combinations (i.e., M2a: IL-4 and IL-13; M2b: LPS and immune complex; M2c: IL-10 and glucocorticoids; M2d: IL-6) [77-79]. Researchers still unintentionally overlooked the sub-classification of macrophages in vivo. Only one study focused on the M2c macrophage in OA and concluded that hyaluronan could significantly increase the number of anti-fibrotic M2c macrophages $\left(\mathrm{F} 4 / 80^{+} \mathrm{CD} 206^{+} \mathrm{CD} 301^{+}\right) 12$ weeks post DMM [55]. Further investigations are thus needed.

The materials and methods in included studies covered the most commonly used molecular biological technologies (shown in Table 2). The phenotypic alterations of macrophage in OA were effectively identified with these technologies, both transcriptionally and translationally. However, the detective methodologies and cellular markers of M0, M1, and M2 macrophages varied and had limitations, and impacted the data interpretation among studies and research models. For instance, the F4/80 was widely adopted as a cellular marker for macrophage in many included studies, but the specify and sensitivity is not that satisfying [80]. The expression of F4/80 varied among mouse mononuclear populations, being very low in the bone marrow $\mathrm{Ly}^{+} \mathrm{c}^{+}$monocyteemanated macrophage, but high in various tissueresident macrophage derived from fetal yolk sac, such as microglia (brain) and Kuffer cells (liver) [80]. We summarized the cellular markers employed in the included studies in Table 4. In the future, the booming development of single-cell methodologies will help to identify the individual cell types at a single-cell level, which could be used to target distinct macrophage populations precisely.

Although standardization of M1/M2 phenotype gave researchers a uniform framework to study macrophages in vitro and made results from different studies comparable, several drawbacks were still concerned. The rigid subdivision of macrophage as M1 and M2 hindered the 
Table 4 Summary of the detected cell surface marker of MO, $\mathrm{M} 1$, and $\mathrm{M} 2$ macrophage

\begin{tabular}{ll}
\hline & Cell surface marker \\
\hline M0 macrophage & CD68; F4/80 \\
M1 macrophage & CD86; CD40; iNOS/NOS2; CCR7; CD11C; CD16/32 \\
M2 macrophage & CD163; MRC; CD206; Arg1; CCL22
\end{tabular}

Abbreviation: CCR7 CC-chemokine receptor 7, Arg1 Arginase1, CCL22 C-C motif chemokine ligand 22, iNOS inducible NO synthase, NOS2 NO Synthase2

understanding of macrophage plasticity in vivo, since classical M1 and M2 polarization were two distinct macrophage subtypes and they were unlikely to occur in a tissue context. For instance, the classical M1/M2 paradigm failed to explain the different transcriptomic changes of human monocyte-derived macrophages and lung-resident alveolar macrophages after stimulated with LPS/IFN- $\gamma$ (M1 inducer) or IL-4/IL-13 (M2 inducer) [81]. These macrophage responses indicated that there remained room for macrophages to be further grouped. Avraham et al. conducted a single-cell RNA-sequencing to show that peritoneal macrophages in the same microenvironment respond differently to the stimulus of salmonella strains that differed by a single gene termed PhoP [82].

The classical concept of the M1/M2 paradigm might be misleading, especially at early stage of inflammation, when tissue-resident and monocyte-derived macrophages coexisted in the local microenvironment. Tissue-resident macrophages expressed relatively higher levels of "M2-like" markers in comparison with mature monocyte-derived macrophages [83, 84]. Without lineage tracing markers, the simultaneous presence of macrophage population in early inflammation (immature monocyte-derived macrophages and few mature tissue-resident macrophages) would be regarded as an "M1-like" polarization tendency due to more immature monocyte-derived macrophages in the mixed population. During weeks-long resolution, monocyte-derived macrophages gradually matured and their phenotype resembled the tissue-resident macrophages. Therefore, the mixed cellular population (mature monocyte-derived and mature tissue-resident macrophages) would display a "shift" towards an "M2-like" phenotype [84]. Thus, in the in vitro study conducted by Menarim et al. [53], we speculated that stimuli (SF or ISF) might fail to mobilize the monocyte-derived macrophages from circulation and incur the insufficiency of the M1-like macrophage.

Recently, Culemann et al. found that in healthy murine and human knee joint, a thin layer of synovium-resident macrophage formed a barrier-like structure, covering the sublining layer of synovium. Disrupting this structure by genetic depletion or pharmacological inhibition of these barrier-forming macrophages exacerbated arthritis progression. Further tracing of these macrophages revealed that these $\mathrm{CX} 3 \mathrm{CR} 1^{+}$lining macrophages were originated from a subtype of synovium-resident interstitial macrophage, instead of monocytes [65]. Although these results were discovered in RA model, it also implied that the critical roles of the synovium-resident macrophage or subchondral bone-resident macrophage is worthy of investigation in $\mathrm{OA}$. They were also the potential cellular targets for further therapeutic design. The recently emerging applications of single-cell RNA sequence or mass cytometry could dissect the exact macrophage phenotypes more than M1/M2 paradigm [57, 85].

\section{Limitation}

The quality of included studies was limited due to the low number of high-level evidence. As mentioned in the discussion, the majority of included studies exerted classical methodologies, thus lacking deep insights into the phenotypic alterations of different subtypes of macrophages.

Secondly, the spontaneous OA models were not included due to lack of reports. For instance, aging model in Guinea pig recapitulates the most common cause of human OA [86]. Researches using this model will enhance the translational value in future study.

Thirdly, due to lack of standardized and wellrecognized marker for identifying different subtypes of macrophages, the results of different studies were not very comparable.

Lastly, the sample size included in our study was small, both in the number of articles included and the number of animal samples used in some included studies. The small sample size made it at the risk of bias and difficult to reach general conclusions.

\section{Conclusion}

In summary, we reviewed the current studies of phenotypic alterations of macrophages in $\mathrm{OA}$ and emphasized the disequilibrium of $\mathrm{M} 1$ and $\mathrm{M} 2$ macrophage during $\mathrm{OA}$, and potential therapies that could rebalance between M1/M2 macrophages. With a more thorough understanding of macrophages and the improvement in detecting methodology, the detailed macrophage subtypes and their individual roles in $\mathrm{OA}$ pathogenesis should be further elucidated.

\section{Supplementary Information}

The online version contains supplementary material available at https://doi. org/10.1186/s13075-021-02457-3.

Additional file 1: Supplemental 1a. Methodological quality assessment protocol 1 used for included animal studies (the number of "yes" answers was counted for each study to give a total score out of 8). Supplemental 1b. Quality assessment for systemic reviews in experimental animal studies. Supplemental 2. Risk of Bias Assessment for in vitro studies according to GRADE Criteria 


\section{Abbreviations}

ACLT: Anterior cruciate ligament transection; BCP: Basic calcium phosphate: BMMC: Bone marrow mononuclear cells; DMM: Destabilization of medial meniscus; HFP: Hoffa's fat pad; IL-1: Interleukin-1; IL-6: Interleukin-6; Lum: Lumican; MaFIA: Macrophage Fas-Induced Apoptosis; mTORC1: Mammalian target of rapamycin complex 1; NP: Nanoparticle: OA: Osteoarthritis; PBMC: Peripheral blood monocytes; PRISMA: Preferred Reporting Items for Systematic Reviews and Meta-Analyses; RA: Rheumatoid arthritis; Rheb1: Ras homolog enriched in brain 1; Rspo2: R-spondin-2; $\mathrm{PGE}_{2}$ : Prostaglandin E2; Sirt1: Silent information regulator 2 ortholog 1; SMM: Synovium-derived macrophage; TGF- $\beta$ : Transforming growth factorbeta; TNF-a: Tumor necrosis factor-alpha; TSC1: Tuberous sclerosis complex 1; WOS: Web of Science

\section{Acknowledgements}

This study was supported by the fundings of $Y Z J$ (the National Key R\&D Program of China, 2019YFA0111900 to YJ), OKL (MWLC Associate Member Programme, Ming Wai Lau Centre of Reparative Medicine of Karolinska Institute to LOK), and CWL (Hong Kong Government Research Grant Council, General Research Fund Reference no. 14104620 to CWL).

\section{Authors' contributions}

All authors listed have read and approved all versions of the manuscript. Conception and design: OKL, XBZ, and HTX. Drafting of the article: XBZ and YFW. Critical revision of the article for important intellectual content: XBZ, OKL, PSY, YZJ, and CWL. The authors read and approved the final version of the manuscript.

\section{Funding}

This study was supported by the Ministry of Science and Technology (the National Key R\&D Program of China, 2019YFA0111900 to YJ), MWLC Associate Member Programme, Ming Wai Lau Centre of Reparative Medicine of Karolinska Institute to LOK., and also by Hong Kong Government Research Grant Council, General Research Fund (Reference no. 14104620 to CWL).

\section{Availability of data and materials}

All data generated or analyzed during this study are included in this published article.

\section{Declarations}

\section{Ethics approval and consent to participate}

Not applicable.

\section{Consent for publication}

Not applicable.

\section{Competing interests}

The authors declare that they have no competing interests.

\section{Author details}

${ }^{1}$ Institute for Tissue Engineering and Regenerative Medicine, The Chinese University of Hong Kong, Hong Kong, China. ${ }^{2}$ Department of Orthopaedics and Traumatology, Faculty of Medicine, The Chinese University of Hong Kong, Hong Kong, China. ${ }^{3}$ School of Biomedical Sciences, Faculty of Medicine, The Chinese University of Hong Kong, Hong Kong, China. ${ }^{4} \mathrm{Li}$ Ka Shing Institute of Health Sciences, Faculty of Medicine, The Chinese University of Hong Kong, Hong Kong, China. ${ }^{5}$ Department of Orthopedics, China Medical University Hospital, Taichung, Taiwan.

Received: 9 June 2020 Accepted: 18 February 2021

Published online: 10 April 2021

\section{References}

1. Chu CR, Millis MB, Olson SA. Osteoarthritis: from palliation to prevention: AOA critical issues. J Bone Joint Surg. 2014;96:e130. https://doi.org/10.2106/ JBJS.M.01209.

2. Hunter DJ, Bierma-Zeinstra S. Osteoarthritis. Lancet. 2019;393(10182):174559. https://doi.org/10.1016/S0140-6736(19)30417-9.
3. Hootman JM, Helmick CG. Projections of US prevalence of arthritis and associated activity limitations. Arthritis Rheum. 2006;54(1):226-9. https://doi. org/10.1002/art.21562.

4. Mobasheri A, Rayman MP, Gualillo O, Sellam J, Van Der Kraan P, Fearon U. The role of metabolism in the pathogenesis of osteoarthritis. Nat Rev Rheumatol. 2017;13(5):302-11. https://doi.org/10.1038/nrrheum.2017.50.

5. Chen D, Shen J, Zhao W, Wang T, Han L, Hamilton JL, et al. Osteoarthritis: toward a comprehensive understanding of pathological mechanism. Bone Res. 2017:5:16044. https://doi.org/10.1038/boneres.2016.44.

6. Zhu X, Chen F, Lu K, Wei A, Jiang Q, Cao W. PPARypreservation via promoter demethylation alleviates osteoarthritis in mice. Ann Rheum Dis. 2019;78(10):1420-9. https://doi.org/10.1136/annrheumdis-2018-214940.

7. Loeser RF, Collins JA, Diekman BO. Ageing and the pathogenesis of osteoarthritis. Nat Rev Rheumatol. 2016;12:412-20. https://doi.org/10.1038/ nrrheum.2016.65.

8. Oo WM, Hunter DJ. Disease modification in osteoarthritis: are we there yet? Clin Exp Rheumatol. 2019;37:135-40.

9. Orlowsky EW, Kraus VB. The role of innate immunity in osteoarthritis: when our first line of defense goes on the offensive. J Rheumatol. 2015;42:363-71. https://doi.org/10.3899/jrheum.140382.

10. Robinson WH, Lepus CM, Wang Q, Raghu H, Mao R, Lindstrom TM, et al. Low-grade inflammation as a key mediator of the pathogenesis of osteoarthritis. Nat Rev Rheumatol. 2016;12:580-92. https://doi.org/10.1038/ nrrheum.2016.136

11. Bondeson J, Wainwright SD, Lauder S, Amos N, Hughes CE. The role of synovial macrophages and macrophage-produced cytokines in driving aggrecanases, matrix metalloproteinases, and other destructive and inflammatory responses in osteoarthritis. Arthritis Res Ther. 2006;8:1-12. https://doi.org/10.1186/ar2099.

12. Blom $A B$, Van Lent $P L$, Libregts $S$, Holthuysen $A E$, Van Der Kraan PM, Van Rooijen $\mathrm{N}$, et al. Crucial role of macrophages in matrix metalloproteinasemediated cartilage destruction during experimental osteoarthritis: involvement of matrix metalloproteinase 3. Arthritis Rheum. 2007;56:147-57. https://doi.org/10.1002/art.22337.

13. Wu C-L, McNeill J, Goon K, Little D, Kimmerling K, Huebner J, et al. Conditional macrophage depletion increases inflammation and does not inhibit the development of osteoarthritis in obese macrophage Fas-induced apoptosis-transgenic mice. Arthritis Rheumatol. 2017;69:1772-83. https://doi. org/10.1002/art.40161.

14. Li K, Nandakumar KS. Macrophages in the activation and resolution of inflammation. In: Nandakumar KS, editor. Autoimmune disorders: risk factors, pathogenesis and treatments, vol. Chapter 6. USA: Nova publishers; 2019. p. 215-43.

15. Davies LC, Jenkins SJ, Allen JE, Taylor PR. Tissue-resident macrophages. Nat Immunol. 2013;14:986-95. https://doi.org/10.1038/ni.2705.

16. Huynh M-LN, Fadok VA, Henson PM. Phosphatidylserine-dependent ingestion of apoptotic cells promotes TGF- $\beta 1$ secretion and the resolution of inflammation. J Clin Invest. 2002;109:41-50. https://doi.org/10.1172/JCl1 1638.

17. Martinez FO, Gordon S. The M1 and M2 paradigm of macrophage activation: time for reassessment. F1000Prime Rep. 2014;6:13. https://doi. org/10.12703/P6-13.

18. Bailey KN, Furman BD, Zeitlin J, Kimmerling KA, Wu C-L, Guilak F, et al. Intraarticular depletion of macrophages increases acute synovitis and alters macrophage polarity in the injured mouse knee. Osteoarthr Cartil. 2020; 28(5):626-38. https://doi.org/10.1016/j.joca.2020.01.015.

19. Momtazi-Borojeni AA, Abdollahi E, Nikfar B, Chaichian S, Ekhlasi-Hundrieser M. Curcumin as a potential modulator of M1 and M2 macrophages: new insights in atherosclerosis therapy. Heart Fail Rev. 2019;24:399-409. https:// doi.org/10.1007/s10741-018-09764-z.

20. Yuan A, Hsiao Y-J, Chen H-Y, Chen H-W, Ho C-C, Chen Y-Y, et al. Opposite effects of M1 and M2 macrophage subtypes on lung cancer progression. Sci Rep. 2015;5:14273. https://doi.org/10.1038/srep14273.

21. Dou C, Ding N, Zhao C, Hou T, Kang F, Cao Z, et al. Estrogen deficiencymediated M2 macrophage osteoclastogenesis contributes to M1/M2 ratio alteration in ovariectomized osteoporotic mice. J Bone Miner Res. 2018;33: 899-908. https://doi.org/10.1002/jbmr.3364.

22. Johnson TA, Singla DK. PTEN inhibitor VO-OHpic attenuates inflammatory M1 macrophages and cardiac remodeling in doxorubicin-induced cardiomyopathy. Am J Physiol Heart Circ Physiol. 2018;315:H1236-49. https://doi.org/10.1152/ajpheart.00121.2018.

23. Moher D, Shamseer L, Clarke M, Ghersi D, Liberati A, Petticrew M, et al. Preferred reporting items for systematic review and meta-analysis protocols 
(PRISMA-P) 2015 statement. Syst Rev. 2015;4(1). https://doi.org/10.1186/204 6-4053-4-1.

24. Babineau J. Product review: Covidence (systematic review software). J Can Heal Libr Assoc. 2014;35:68.

25. Wells K, Littell JH. Study quality assessment in systematic reviews of research on intervention effects. Res Soc Work Pract. 2009;19:52-62.

26. Borges GÁ, Rêgo DF, Assad DX, Coletta RD, De Luca Canto G, Guerra ENS. In vivo and in vitro effects of curcumin on head and neck carcinoma: a systematic review. J Oral Pathol Med. 2017;46:3-20. https://doi.org/10.1111/ jop. 12455.

27. Hong-Tao X, Chien-Wei L, Yan LM, Yu-Fan W, Shu-Hang Patrick Y, KuangSheng OL. The shift in macrophages polarization after tendon injury: a systematic review. J Orthop Transl. 2019;21:24-34. https://doi.org/10.1016/j. jot.2019.11.009.

28. Shahmohammadi M, Shariatpanahi ZV, HajimohammadebrahimKetabforoush M. In vitro and in vivo antitumor activity of vitamin D3 in malignant gliomas: a systematic review. Int J Cancer Manag. 2020;13(2): e94542. https://doi.org/10.5812/ijcm.94542.

29. Mahon OR, Kelly DJ, McCarthy GM, Dunne A. Osteoarthritis-associated basic calcium phosphate crystals alter immune cell metabolism and promote M1 macrophage polarization. Osteoarthr Cartil. 2019;S1063-4584(1019):31247-6. https://doi.org/10.1016/j.joca.2019.10.010.

30. Zhou F, Mei J, Han X, Li H, Yang S, Wang M, et al. Kinsenoside attenuates osteoarthritis by repolarizing macrophages through inactivating NF-kappa B/MAPK signaling and protecting chondrocytes. Acta Pharm Sin B. 2019;9: 973-85. https://doi.org/10.1016/j.apsb.2019.01.015.

31. Jablonski CL, Leonard C, Salo P, Krawetz RJ. CCL2 but not CCR2 is required for spontaneous articular cartilage regeneration post-injury. J Orthop Res. 2019:37:2561-74. https://doi.org/10.1002/jor.24444.

32. Yarnall BW, Chamberlain CS, Hao Z, Muir P. Proinflammatory polarization of stifle synovial macrophages in dogs with cruciate ligament rupture. Vet Surg. 2019;48:1005-12. https://doi.org/10.1111/vsu.13261.

33. Haltmayer E, Ribitsch I, Gabner S, Rosser J, Gueltekin S, Peham J, et al. Coculture of osteochondral explants and synovial membrane as in vitro model for osteoarthritis. PLoS One. 2019;14:1-19. https://doi.org/10.1371/journal. pone.0214709.

34. Liu B, Zhang M, Zhao J, Zheng M, Yang H. Imbalance of M1/M2 macrophages is linked to severity level of knee osteoarthritis. Exp Ther Med. 2018;16:5009-14. https://doi.org/10.3892/etm.2018.6852.

35. Sambamurthy N, Zhou C, Nguyen V, Smalley R, Hankenson KD, Dodge GR, et al. Deficiency of the pattern-recognition receptor CD14 protects against joint pathology and functional decline in a murine model of osteoarthritis. PLoS One. 2018;e206217:13. https://doi.org/10.1371/journal.pone.0206217.

36. Wang W, Lin $X, X u H$, Sun W, Bouta EM, Zuscik MJ, et al. Attenuated joint tissue damage associated with improved synovial lymphatic function following treatment with Bortezomib in a mouse model of experimental posttraumatic osteoarthritis. Arthritis Rheumatol. 2019;71:244-57. https://doi. org/10.1002/art.40696.

37. Zhang H, Lin C, Zeng C, Wang Z, Wang H, Lu J, et al. Synovial macrophage M1 polarisation exacerbates experimental osteoarthritis partially through $\mathrm{R}$ spondin-2. Ann Rheum Dis. 2018;77(10):1524-34. https://doi.org/10.1136/a nnrheumdis-2018-213450.

38. Timur UT, Caron MMJ, Bastiaansen-Jenniskens YM, Welting TJM, van Rhijn LW, van Osch GJVM, et al. Celecoxib-mediated reduction of prostanoid release in Hoffa's fat pad from donors with cartilage pathology results in an attenuated inflammatory phenotype. Osteoarthr Cartil. 2018;26:697-706. https://doi.org/10.1016/j.joca.2018.01.025.

39. Topoluk N, Steckbeck K, Siatkowski S, Burnikel B, Tokish J, Mercuri J. Amniotic mesenchymal stem cells mitigate osteoarthritis progression in a synovial macrophage-mediated in vitro explant coculture model. J Tissue Eng Regen Med. 2018;12:1097-110. https://doi.org/10.1002/term.2610.

40. Manferdini C, Paolella F, Gabusi E, Gambari L, Piacentini A, Filardo G, et al. Adipose stromal cells mediated switching of the pro-inflammatory profile of M1-like macrophages is facilitated by PGE2: in vitro evaluation. Osteoarthr Cartil. 2017;25:1161-71. https://doi.org/10.1016/j.joca.2017.01.011.

41. Pal S, Konkimalla VB. Sulforaphane regulates phenotypic and functional switching of both induced and spontaneously differentiating human monocytes. Int Immunopharmacol. 2016;35:85-98. https://doi.org/10.1016/j. intimp.2016.03.008.

42. Siebelt M, Korthagen N, Wei W, Groen H, Bastiaansen-Jenniskens Y, Muller $\mathrm{C}$, et al. Triamcinolone acetonide activates an anti-inflammatory and folate receptor-positive macrophage that prevents osteophytosis in vivo. Arthritis Res Ther. 2015;17:352. https://doi.org/10.1186/s13075-015-0865-1.

43. Fahy N, de Vries-van Melle ML, Lehmann J, Wei W, Grotenhuis N, Farrell E, et al. Human osteoarthritic synovium impacts chondrogenic differentiation of mesenchymal stem cells via macrophage polarisation state. Osteoarthr Cartil. 2014;22:1167-75. https://doi.org/10.1016/j.joca.2014.05.021.

44. Tsuneyoshi Y, Tanaka M, Nagai T, Sunahara N, Matsuda T, Sonoda T, et al. Functional folate receptor beta-expressing macrophages in osteoarthritis synovium and their M1/M2 expression profiles. Scand J Rheumatol. 2012;41: 132-40. https://doi.org/10.3109/03009742.2011.605391.

45. Zhang S, Chuah SJ, Lai RC, Hui JHP, Lim SK, Toh WS. MSC exosomes mediate cartilage repair by enhancing proliferation, attenuating apoptosis and modulating immune reactivity. Biomaterials. 2018;156:16-27. https://doi. org/10.1016/j.biomaterials.2017.11.028.

46. Hu Y, Gui Z, Zhou Y, Xia L, Lin K, Xu Y. Quercetin alleviates rat osteoarthritis by inhibiting inflammation and apoptosis of chondrocytes, modulating synovial macrophages polarization to M2 macrophages. Free Radic Biol Med. 2019;145:146-60. https://doi.org/10.1016/j.freeradbiomed.2019.09.024.

47. Dai M, Sui B, Xue Y, Liu X, Sun J. Cartilage repair in degenerative osteoarthritis mediated by squid type II collagen via immunomodulating activation of M2 macrophages, inhibiting apoptosis and hypertrophy of chondrocytes. Biomaterials. 2018;180:91-103. https://doi.org/10.1016/j.biomaterials.2018.07.011.

48. Barreto G, Senturk B, Colombo L, Brück O, Neidenbach P, Salzmann G, et al. Lumican is upregulated in osteoarthritis and contributes to TLR4-induced pro-inflammatory activation of cartilage degradation and macrophage polarization. Osteoarthr Cartil. 2020;28:92-101. https://doi.org/10.1016/j. joca.2019.10.011.

49. Kraus VB, McDaniel G, Huebner JL, Stabler TV, Pieper CF, Shipes SW, et al. Direct in vivo evidence of activated macrophages in human osteoarthritis. Osteoarthr Cartil. 2016;24:1613-21. https://doi.org/10.1016/j.joca.2016.04.010.

50. Utomo L, van Osch GJVM, Bayon Y, Verhaar JAN, Bastiaansen-Jenniskens YM Guiding synovial inflammation by macrophage phenotype modulation: an in vitro study towards a therapy for osteoarthritis. Osteoarthr Cartil. 2016;24: 1629-38. https://doi.org/10.1016/j.joca.2016.04.013.

51. Alvarado-Vazquez PA, Bernal L, Paige CA, Grosick RL, Moracho Vilrriales C, Ferreira DW, et al. Macrophage-specific nanotechnology-driven CD163 overexpression in human macrophages results in an $\mathrm{M} 2$ phenotype under inflammatory conditions. Immunobiology. 2017;222:900-12. https://doi.org/1 0.1016/j.jmbio.2017.05.011.

52. Miyaji N, Nishida K, Tanaka T, Araki D, Kanzaki N, Hoshino Y, et al. Inhibition of knee osteoarthritis progression in mice by administering SRT2014, an activator of silent information regulator 2 Ortholog 1. Cartilage. 2020: 1947603519900795. https://doi.org/10.1177/1947603519900795.

53. Menarim BC, Gillis KH, Oliver A, Mason C, Werre SR, Luo X, et al. Inflamed synovial fluid induces a homeostatic response in bone marrow mononuclear cells in vitro: implications for joint therapy. FASEB J. 2020;34: 4430-44. https://doi.org/10.1096/fj.201902698R.

54. Zhou F, Mei J, Yang S, Han X, Li H, Yu Z, et al. Modified ZIF-8 nanoparticles attenuate osteoarthritis by reprogramming the metabolic pathway of synovial macrophages. ACS Appl Mater Interfaces. 2020;12(2):2009-22. https://doi.org/10.1021/acsami.9b16327.

55. Shu CC, Zaki S, Ravi V, Schiavinato A, Smith MM, Little CB. The relationship between synovial inflammation, structural pathology, and pain in post-traumatic osteoarthritis: differential effect of stem cell and hyaluronan treatment. Arthritis Res Ther. 2020;22:1-13. https://doi.org/10.1186/s13075-015-0865-1.

56. Nicholson LB. The immune system. Essays Biochem. 2016;60:275-301.

57. Watanabe $S$, Alexander M, Misharin AV, Budinger GRS. The role of macrophages in the resolution of inflammation. J Clin Invest. 2019;129: 2619-28. https://doi.org/10.1172/JCl124615.

58. Wenham CYJ, Conaghan PG. The role of synovitis in osteoarthritis. Ther Adv Musculoskelet Dis. 2010;2:349-59. https://doi.org/10.1177/1759720X10378373.

59. Griffin $T M$, Scanzello CR, Griffin TM, Griffin TM. Innate inflammation and synovial macrophages in osteoarthritis pathophysiology. Clin Exp Rheumatol. 2019;37 Suppl 120(5):57-63.

60. Clockaerts S, Bastiaansen-Jenniskens YM, Runhaar J, Van Osch GJVM, Van Offel JF, Verhaar JAN, et al. The infrapatellar fat pad should be considered as an active osteoarthritic joint tissue: a narrative review. Osteoarthr Cartil. 2010:18:876-82. https://doi.org/10.1016/j.joca.2010.03.014.

61. Glasson SS, Blanchet TJ, Morris EA. The surgical destabilization of the medial meniscus (DMM) model of osteoarthritis in the 129/SvEv mouse. Osteoarthr Cartil. 2007;15:1061-9. https://doi.org/10.1016/j.joca.2007.03.006. 
62. Magri C, Schramme M, Febre M, Cauvin E, Labadie F, Saulnier N, et al. Comparison of efficacy and safety of single versus repeated intra-articular injection of allogeneic neonatal mesenchymal stem cells for treatment of osteoarthritis of the metacarpophalangeal/metatarsophalangeal joint in horses: a clinical pilot study. Fiorina P, editor PLoS One 2019;14:e0221317. doi:https://doi.org/10.1371/journal.pone.0221317.

63. Wynn TA, Barron L, Thompson RW, Madala SK, Wilson MS, Cheever AW, et al. Quantitative assessment of macrophage functions in repair and fibrosis. Curr Protoc Immunol. 2011; Chapter 14:14.22. https://doi.org/10.1 002/0471142735.im1422s93.

64. Croft AP, Campos J, Jansen K, Turner JD, Marshall J, Attar M, et al. Distinct fibroblast subsets drive inflammation and damage in arthritis. Nature. 2019; 570:246-51. https://doi.org/10.1038/s41586-019-1263-7.

65. Culemann S, Grüneboom A, Nicolás-Ávila JÁ, Weidner D, Lämmle KF, Rothe $T$, et al. Locally renewing resident synovial macrophages provide a protective barrier for the joint. Nature. 2019;572(7771):670-5. https://doi. org/10.1038/s41586-019-1471-1.

66. Cosenza S, Ruiz M, Toupet K, Jorgensen C, Noël D. Mesenchymal stem cells derived exosomes and microparticles protect cartilage and bone from degradation in osteoarthritis. Sci Rep. 2017;7:1-12. https://doi.org/10.1038/ s41598-017-15376-8.

67. Kong L, Zheng LZ, Qin L, Ho KKW. Role of mesenchymal stem cells in osteoarthritis treatment. J Orthop Transl. 2017;9:89-103. https://doi.org/10.1 016/j.jot.2017.03.006

68. Chahal J, Gómez-Aristizábal A, Shestopaloff K, Bhatt S, Chaboureau A, Fazio $A$, et al. Bone marrow mesenchymal stromal cells in patients with osteoarthritis results in overall improvement in pain and symptoms and reduces synovial inflammation. Stem Cells Transl Med. 2019;8(8):746-57. https://doi.org/10.1002/sctm.18-0183.

69. Hofer HR, Tuan RS. Secreted trophic factors of mesenchymal stem cells support neurovascular and musculoskeletal therapies. Stem Cell Res Ther. 2016;7:1-14. https://doi.org/10.1186/s13287-016-0394-0.

70. Yeadon C, Karsh J. Lymphapheresis in rheumatoid arthritis. The clinical and laboratory effects of a limited course of cell depletion. Clin Exp Rheumatol. 1983;1:119-24

71. Hahn G, Stuhlmüller B, Hain N, Kalden JR, Pfizenmaier K, Burmester GR. Modulation of monocyte activation in patients with rheumatoid arthritis by leukapheresis therapy. J Clin Invest. 1993;91:862-70. https://doi.org/10.1172/ JCl116307.

72. Degboé Y, Rauwel B, Baron M, Boyer J-F, Ruyssen-Witrand A, Constantin A, et al. Polarization of rheumatoid macrophages by TNF targeting through an IL-10/STAT3 mechanism. Front Immunol. 2019;10:3. https://doi.org/10.3389/ fimmu.2019.00003.

73. Tardito S, Martinelli G, Soldano S, Paolino S, Pacini G, Patane M, et al. Macrophage M1/M2 polarization and rheumatoid arthritis: a systematic review. Autoimmun Rev. 2019;18:102397. https://doi.org/10.1016/j.autrev.201 9.102397.

74. Blom AB, van Lent PLEM, Holthuysen AEM, van der Kraan PM, Roth J, van Rooijen N, et al. Synovial lining macrophages mediate osteophyte formation during experimental osteoarthritis. Osteoarthr Cartil. 2004;12:627-35. https:// doi.org/10.1016/j.joca.2004.03.003.

75. He W, Kapate N, Shields CW, Mitragotri S. Drug delivery to macrophages: a review of targeting drugs and drug carriers to macrophages for inflammatory diseases. Adv Drug Deliv Rev. 2020;165-166:15-40. https://doi. org/10.1016/j.addr.2019.12.001.

76. Wang LX, Zhang SX, Wu HJ, Rong XL, Guo J. M2b macrophage polarization and its roles in diseases. J Leukoc Biol. 2019;106:345-58. https://doi.org/10.1 002/JLB.3RU1018-378RR.

77. MacParland SA, Tsoi KM, Ouyang B, Ma X-Z, Manuel J, Fawaz A, et al. Phenotype determines nanoparticle uptake by human macrophages from liver and blood. ACS Nano. 2017;11:2428-43. https://doi.org/10.1021/acsna no.6b06245

78. Bianchini R, Roth-Walter F, Ohradanova-Repic A, Flicker S, Hufnagl K, Fischer $\mathrm{MB}$, et al. lgG4 drives M2a macrophages to a regulatory M2b-like phenotype: potential implication in immune tolerance. Allergy. 2019;74:48394. https://doi.org/10.1111/all.13635.

79. Liberale L, Dallegri F, Montecucco F, Carbone F. Pathophysiological relevance of macrophage subsets in atherogenesis. Thromb Haemost. 2017; 117:07-18. https://doi.org/10.1160/TH16-08-0593.
80. Wynn TA, Chawla A, Pollard JW. Macrophage biology in development, homeostasis and disease. Nature. 2013:496:445-55. https://doi.org/10.1038/ nature12034.

81. Xue J, Schmidt SV, Sander J, Draffehn A, Krebs W, Quester I, et al. Transcriptome-based network analysis reveals a spectrum model of human macrophage activation. Immunity. 2014;40:274-88. https://doi.org/10.1016/j. immuni.2014.01.006

82. Avraham R, Haseley N, Brown D, Penaranda C, Jijon HB, Trombetta JJ, et al. Pathogen cell-to-cell variability drives heterogeneity in host immune responses. Cell. 2015;162:1309-21. https://doi.org/10.1016/j.cell.2015.08.027.

83. Lavin Y, Winter D, Blecher-Gonen R, David E, Keren-Shaul H, Merad M, et al. Tissue-resident macrophage enhancer landscapes are shaped by the local microenvironment. Cell. 2014;159:1312-26. https://doi.org/10.1016/j.cell.2 014.11.018.

84. Misharin AV, Morales-Nebreda L, Reyfman PA, Cuda CM, Walter JM, McQuattie-Pimentel AC, et al. Monocyte-derived alveolar macrophages drive lung fibrosis and persist in the lung over the life span. J Exp Med. 2017;214: 2387-404. https://doi.org/10.1084/jem.20162152.

85. Reyfman PA, Walter JM, Joshi N, Anekalla KR, McQuattie-Pimentel AC, Chiu $\mathrm{S}$, et al. Single-cell transcriptomic analysis of human lung provides insights into the pathobiology of pulmonary fibrosis. Am J Respir Crit Care Med. 2019:199:1517-36. https://doi.org/10.1164/rccm.201712-24100C.

86. Fang $\mathrm{H}$, Beier $\mathrm{F}$. Mouse models of osteoarthritis: modelling risk factors and assessing outcomes. Nat Rev Rheumatol. 2014;10:413-21. https://doi.org/1 0.1038/nrrheum.2014.46.

\section{Publisher's Note}

Springer Nature remains neutral with regard to jurisdictional claims in published maps and institutional affiliations. 